\title{
Distribusi Serangga Hama pada Lahan Pertanaman Kedelai (Glicyne max) Fase Generatif di Unit Pelaksana Teknis Pengembangan Benih Palawija Singosari, Malang

\author{
Distribution of Pest Insect at Soybean (Glycine max) Plant Generative Phase \\ of Technical Implementation of Palawija Seed Development Unit of Singosari, \\ Malang
}

Siti Marirotuz Zahro' ${ }^{*}$, , Ari Hayati $\left.{ }^{1 * *}\right)$, Hasan Zayadi ${ }^{3}$

1,2,3 Jurusan Biologi Fakultas Matematika dan Ilmu Pengetahuan Alam Universitas Islam Malang

\begin{abstract}
ABSTRAK
Serangga hama merupakan istilah yang digunakan untuk menunjukkan serangga-serangga yang berpotensi sebagai hama yang memiliki aktivitas yang berpotensi menimbulkan kerugian secara ekonomis dalam suatu agroekosistem, baik karena aktivitasnya merusak secara langsung ataupun tidak langsung. Tujuan dari penelitian ini yaitu untuk mengetahui jenis, distribusi, dan faktor abiotik yang mempengaruhi distribusi serangga hama yang ditemukan pada tanaman kedelai di Unit Pelaksana Teknis Pengembangan Benih Palawija Singosari, Malang. Penelitian ini menggunakan metode deskriptif dengan melakukan pengamatan serangga hama pada tanaman kedelai secara langsung (visual). Teknik pengambilan sampel serangga hama yang digunakan adalah teknik langsung perhabitat. Hasil penelitian menunjukkan bahwa serangga hama yang ditemukan pada tanaman kedelai fase generatif ada 4 spesies yaitu Spodoptera litura, Chrysodeixis chalcites, Lamprosema indicata, dan Phaedonia inclusa. Keempat spesies tersebut pada pertanaman kedelai berdistribusi dengan pola seragam (uniform) berdasarkan nilai hasil perhitungan Indeks Morishita pada tiap spesies menunjukkan angka di bawah 1 yaitu dengan nilai rata-rata tiap spesies mulai dari yang tertinggi ke yang terendah adalah 0,2 (L. indicata); 0,19 ( $P$. inclusa); 0,17 (C. chalcites); dan 0,15 (S. litura). Berdasarkan hasil analisis data korelasi, faktor abiotik yang diukur (suhu dan kelembaban) tidak berpengaruh terhadap pola sebaran individu serangga hama pada tanaman kedelai.
\end{abstract}

Kata kunci: Pola sebaran, Serangga hama, dan Kedelai.

\section{ABSTRACT}

Pest insects are a term used to refer to insects that potentially as pests, which have the potential activity to cause harm in an agro-ecosystem, either because its activity is damaging directly or indirectly. The purpose of this research is to know the type, distribution, and abiotic factors that affect the distribution of pest insects found in soybean plants of generative phase at technical implementation of Palawija Seeds Development unit, Singosari, Malang. This research uses descriptive method. Observation of pest insects on soybean plants is conducted directly (visual), based on the presence of pest insects that are considered to represent the soybean plant. The sample taking technique of pest insects uses direct technique per habitat. The results showed that pest insect species are found in generative phase of soybean plants were Spodoptera litura, Chrysodeixis chalcites, Lamprosema indicata, and Phaedonia inclusa. The pest insects were uniform distributing pattern which the average values of all species per week of $\underline{\mathrm{S}}$. litura, $\mathrm{L}$. indicate, $\mathrm{C}$. chalcites, and $\mathrm{P}$. inclusa, in soybean plants are $0.15,0.2,0.17$, and 0.19. Based on the results of correlation data analysis, abiotic factors measured temperature and humidity did not affect to the pattern of individual pest insect distribution on soybean plants.

Keywords: Distribution pattern, Pest insect, and Soybean.

1*) Siti Marirotuz Zahro', Jurusan Biologi FMIPA UNISMA, Jl. MT Haryono 193, Malang 65144. +6285745958459 and email mariroh.azzahra23@gmail.com

${ }^{2 * *}$ Dra. Ari Hayati, MP, Jurusan Biologi FMIPA UNISMA, Jl. MT Haryono 193, Malang 65144. +6281803844667 and e-mailaridaniel@yahoo.com

Diterima Tanggal 20 Agustus 2017 - Diterbitkan Tanggal 25 Januari 2020 


\section{Pendahuluan}

Kedelai merupakan sebuah tanaman palawija yang ada di Indonesia sejak sekitar 100 tahun yang lalu. Kedelai kebanyakan digunakan untuk industri pangan, antara lain tahu dan tempe yang telah menjadi menu utama sebagian besar masyarakat Indonesia. Kedelai untuk saat ini masih merupakan komoditi penting bagi masyarakat dan masalah pemenuhan kebutuhan di dalam negeri masih dipenuhi dari impor. Kenaikan impor dan penurunan penyediaan produksi kedelai di dalam negeri menyebabkan pemerintah berupaya untuk mencapai swasembada kedelai agar ketergantungan produk impor dapat ditekan atau bahkan dikurangi [1]. Di Jawa Timur, pada tahun 2011 sampai 2015 terjadi kenaikan dan penurunan setiap tahunnya, yaitu dengan jumlah produksi 366.999 ton/thn, 361.986 ton/thn, 329.461 ton/thn, 355.464 ton/thn, dan 344.998 ton/thn.

Permasalahan mengenai penurunan hasil produksi tanaman kedelai dapat disebabkan oleh beberapa faktor, salah satunya yaitu akibat dari serangan OPT (Organisme Pengganggu Tanaman) yang dapat berupa mikroorganisme dan serangga hama. Serangga hama merupakan istilah yang digunakan untuk menunjukkan serangga-serangga yang berpotensi sebagai hama. Serangga-serangga ini memiliki aktivitas yang berpotensi untuk menimbulkan kerugian secara ekonomis dalam suatu agroekosistem, baik karena aktivitasnya merusak secara ataupun tidak langsung.

Serangga hama yang ditemukan pada tanaman kedelai di Kecamatan Balong-Ponorogo yaitu Aphis sp., Phaedonia inclusa, Riptortus linearis, Nezara viridula dan Ophiomyia phaseoli [2]. Dengan adanya serangga hama yang ditemukan di lahan pertanaman kedelai maka perlu adanya pengendalian hama secara terpadu guna menekan jumlah populasi serangga hama agar tetap dalam ambang batas kendali hama.

Pengendalian hama terpadu merupakan suatu kombinasi beberapa cara pengendalian yang bertujuan agar populasi atau tingkat kerusakan hama berada di bawah nilai ambang batas kendali, artinya populasi atau tingkat kerusakan pada tanaman sangat ringan [1]. Dalam kajian ekologi populasi memiliki arti sekelompok individu dari satu spesies yang hidup di daerah umum yang sama. Anggotaanggota populasi mengandalkan sumber daya yang sama yang dipengaruhi oleh faktor-faktor lingkungan yang serupa, serta berkemungkinan berinteraksi dan berbiak dengan satu sama lain. Populasi memiliki perbatasan spesifik dan ukuran spesifik (jumlah individu yang hidup dalam perbatasan tersebut) [3]. Dalam kaitannya dengan ruang yaitu khususnya skala kecil, individu-individu di dalam populasi menyebar dengan tiga pola meliputi acak (random), seragam (uniform) dan mengelompok (clumped). Penyebaran acak terjadi jika individu-individu dalam populasi dapat hidup dimana saja di dalam area yang ditempati oleh populasi tersebut. Penyebaran seragam terjadi jika individu-individu tersebar secara seragam dalam area, dan penyebaran dikatakan mengelompok jika individu di dalam populasi lebih mudah ditemukan pada area tertentu dibandingkan pada areal yang lain [4].

Penelitian mengenai serangga hama pada tanaman kedelai selama ini masih mengkaji tentang jenis-jenis serangga hama yang ada pada tanaman kedelai secara umum. Studi populasi, khususnya mengenai distribusi individu tiap populasi dari serangga hama pada tanaman kedelai adalah salah satu kajian yang dapat dijadikan sebagai langkah awal dalam melakukan tindakan pencegahan terhadap serangan serangga hama tersebut.

\section{Material dan Metode}

Lahan pertanaman kedelai adalah di Unit Pelaksana Teknis (UPT) Pengembangan Benih Palwaija Singosari, Malang. Bahan dan alat yang digunakan adalah pertanaman kedelai, tali rafia, alat tulis, kamera, kaca pembesar (lup), hand counter, thermometer dan alat pengukur kelmababan (hygrometer).

Penelitian ini dilakukan dengan menggunakan metode deskriptif. Pengamatan serangga hama pada tanaman kedelai dilakukan secara langsung (visual), berdasarkan keberadaan serangga hama yang dianggap mewakili pertanaman kedelai. Teknik pengambilan sampel serangga hama dilakukan menggunakan teknik langsung perhabitat. 
Penelitian ini dilakukan dengan 3 langkah yaitu: persiapan, pelaksanaan, dan analisis data. Persiapan dilakukan dengan melakukan survey tempat untuk menentukan lokasi penelitian dan tanaman yang diamati. Penelitian dilakukan di lahan pertanaman kedelai yang telah memasuki fase generatif yang ditandai dengan adanya bunga dan buah pada lahan seluas $\pm 500 \mathrm{~m}^{2}$. Pada lahan seluas $\pm 500 \mathrm{~m}^{2}$ terdapat 5 petak pertanaman kedelai dalam bentuk bedengan dengan ukuran $4 \times 5 \mathrm{~m}$. Dari 5 petak bedengan tersebut ditentukan petak pengambilan sampel sebanyak 5 plot dengan ukuran masingmasing plot yaitu $1 \mathrm{~m}^{2}$.

Tanaman yang digunakan dalam pengambilan sampel adalah tanaman kedelai varietas anjasmoro yang memasuki fase generatif yang ditandai dengan munculnya bunga dan buah. Pengamatan populasi serangga hama pada tanaman kedelai dilakukan dengan cara melihat langsung jenis serangga hama yang terdapat pada tanaman kedelai yang ada pada tiap petak contoh dengan bantuan kaca pembesar (lup). Pengamatan dilakukan setiap satu minggu sekali pada pagi hari (pukul 06:00 WIB).

Analisis data yang digunakan adalah kuantitatif yaitu data dimasukan dalam tabel dan diolah secara tabulasi. Data yang diperoleh dianalisis menggunakan parameter ekologi dan Indeks Sebaran Morishita, serta dilakukan analisis korelasi antara faktor abiotik dengan nilai Indeks Morishita serangga hama. Faktor abiotik dianalisis secara deskriptif serta dilakukan identifikasi serangga hama pada tanaman kedelai dengan mendeskripsikan ciri-ciri dari serangga hama yang ditemukan menggunakan buku identifikasi serangga [5] [6] sampai pada tingkatan spesies.

\title{
Hasil dan Diskusi
}

Serangga hama yang ditemukan pada tanaman kedelai fase generatif di UPT Pengembangan Benih Palawija Singosari, Malang meliputi dua Ordo, dua Famili, dan empat Spesies yaitu, Spodoptera litura dengan jumlah individu 108, Chrysodeixis Chalcites dengan jumlah individu 65, Lamprosema indicata dengan jumlah individu 81, dan Phaedonia inclusa dengan jumlah individu 174. Tiga dari keempat spesies tersebut dalam klasifikasinya temasuk dalam Ordo Lepidoptera dan Famili Noctuidae yaitu $S$. litura, C. chalcites, dan Lamprosema indicate. Sedangkan satu dari empat spesies tersebut termasuk dalam Ordo Coleoptera dan Famili Chrysomelidae yaitu P. inclusa.

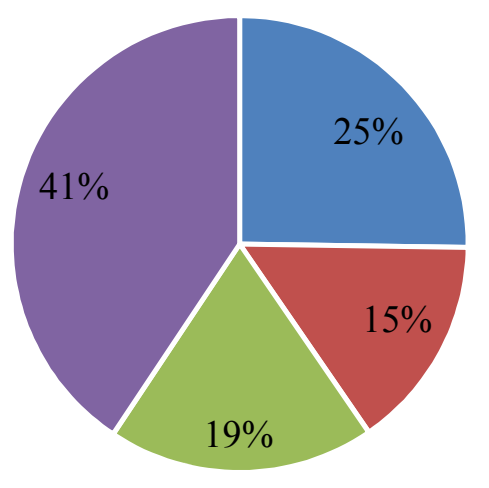

\author{
- Spodoptera \\ litura \\ - Chrysodeixis \\ chalcites \\ - Lamprosema \\ indicata \\ - Phaedonia \\ inclusa
}

Gambar 1. Persentase Jumlah Individu Serangga Hama pada Tanaman Kedelai di UPT Pengembangan Benih Palawija Singosari, Malang.

Berdasarkan Gambar 1. di atas dapat dilihat bahwa jumlah individu yang ditemukan selama pengamatan paling banyak adalah dari spesies Phaedonia inclusa (41\%), kemudian Spodoptera litura (25\%), Lamprosema indicata (19\%), dan Chrysodeixis calcites (15\%). 

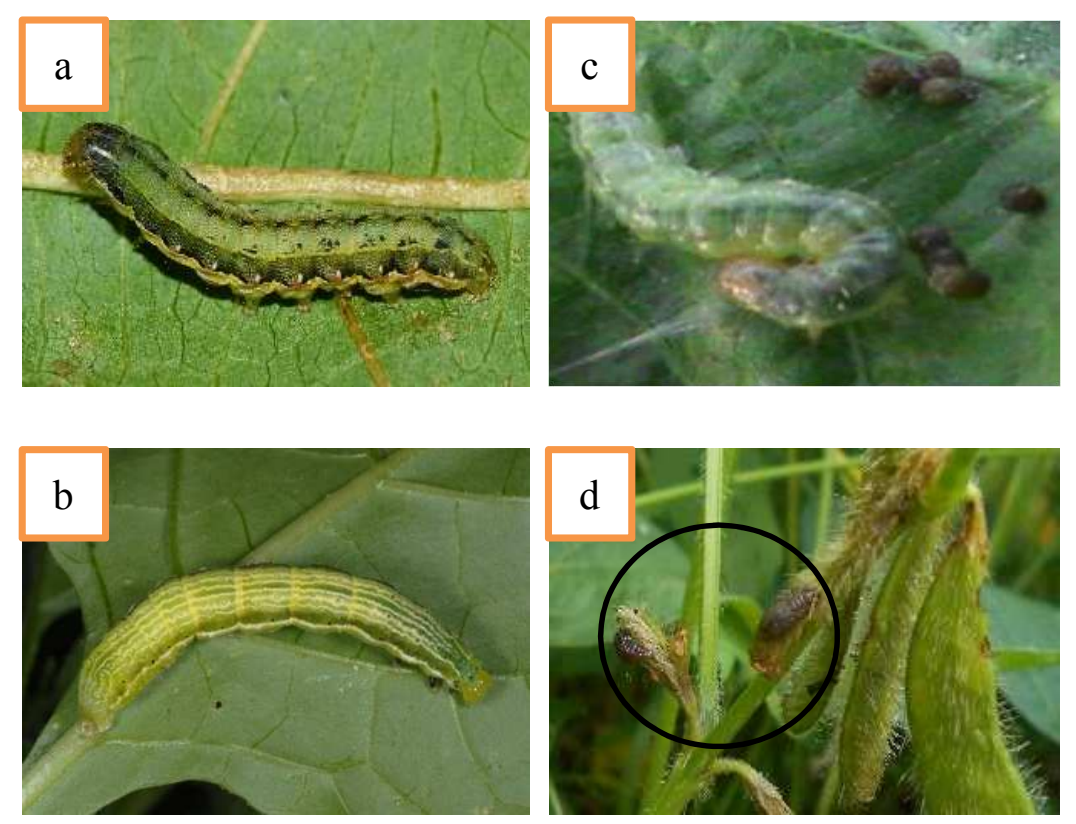

Gambar 2. Morfologi Serangga Hama pada Tanaman Kedelai di UPT Pengembangan Benih Palawija Singosari, Malang

Keterangan: a) Larva L. indicata;

b) Larva P. inclusa;

c) Larva $C$. chalcites;

d) Larva S. litura

Deskripsi Serangga Hama: Serangga hama yang ditemukan pada tanaman kedelai di UPT Pengembangan Benih Palawija Singosari, Malang dapat dideskripsikan sebagai berikut.

\section{a. Spodoptera litura}

Larva merusak daun dengan meninggalkan sisa-sisa pada epidermis bagian atas (transparan) dan tulang daun, dan juga dapat membentuk lubang-lubang daun yang ukurannya besar [7].

\section{b. Chrysodeixis chalcites}

Ulat $P$. chalcites Esp. (=C. chalcites) atau dikenal juga sebagai tobacco and vegetable (tomato, cabbage) looper mulai dari kepala berwarna hijau dengan garis berwarna putih/cerah sepanjang bagian sisi tubuhnya. Larva yang sudah besar panjangnya mencapai $3 \mathrm{~cm}$, mempunyai dua pasang tungkai palsu pada abdomen bagian depan (toraks) dan sepasang pada bagian belakang. Tubuh ulat jengkal menyempit pada bagian ujungnya dengan kepala berukuran kecil.

\section{c. Lamprosema indicata}

Ulat penggulung daun kedelai Lamprosema indicata Fabricius (Lepidoptera; Noctuidae) juga dapat menimbulkan kerusakan yang sangat parah pada tanaman kedelai. Gejala serangan dari hama ulat penggulung daun kedelai adalah daun-daun tergulung menjadi satu dan jika gulungan dibuka, akan terdapat ulat atau kotorannya yang berwarna coklat hitam. Ulat ini membentuk gulungan daun dengan cara merekatkan daun yang satu dengan yang lainnya dari sisi bagian dalam dengan zat perekat yang dihasilkannya. Di dalam gulungan daun, ulat ini memakan daun hingga tersisa tulang daunnya. Ulat ini berwarna hijau, licin, transparan dan agak mengkilap serta pada bagian punggung (toraks) terdapat bintik hitam dan panjang tubuhnya mencapai sekitar $20 \mathrm{~mm}$.

\section{d. Phaedonia inclusa}

P. inclusa, stadium larva hanya bisa hidup di tanaman kedelai sedangkan imago bisa hidup di tanaman selain kedelai yang ada disekitar pertanaman kedelai tersebut. Larva $P$. inclusa yang 
tidak bisa berpindah dari pertanaman kedelai mengakibatkan kerusakan tanaman yang serius karena dalam delapan hari masa hidupnya, larva $P$. inclusa dapat memakan banyak bagian dari tanaman kedelai mulai dari pucuk daun, bunga, dan polong. Dan kebanyakan memakan polong yang masih muda.

Jika dilihat dari klasifikasinya, $P$. inclusa termasuk dalam spesies yang merupakan tipe polyphagus yaitu spesies yang memakan beberapa jenis tanaman. Kumbang $P$. inclusa dapat memakan beberapa jenis tanaman diduga karena ada perbedaan antara masa hidup tanaman kedelai dengan masa hidup kumbang tersebut. Kedelai memiliki masa hidup sekitar 82.5-92.5 hari. Sedangkan pada saat imago saja $P$. inclusa dapat bertahan hidup lebih dari 5 bulan. Sehingga pada saat pasca panen tanaman kedelai kumbang $P$. inclusa membutuhkan tanaman lain agar tetap dapat melangsungkan siklus hidupnya.

Pada umumnya, serangga hampir makan segala macam, tidak terbatas makanan, dan makan dalam banyak cara yang berbeda-beda. Serangga pemakan tumbuhan memakan hampir setiap bagian tumbuhan, serangga pemakan tumbuhan ini dapat memakan bagian luar dari tumbuh-tumbuhan, atau mereka dapat menggali lubang masuk dalam tubuh tumbuhan [6]. Selanjutnya, serangga banyak yang berbahaya atau berperan sebagai perusak. Mereka menyerang berbagai tumbuh-tumbuhan yang sedang tumbuh, termasuk tanaman yang bernilai bagi kemanusiaan, dan makan tumbuh-tumbuhan itu, merusakkan atau membunuh mereka atau menularkan penyakit pada tanaman. Serangga-serangga fitofagus (atau herbivor) makan dengan cara yang berbeda dan pada bagian tumbuh-tumbuhan yang berbeda. Serangga-serangga fitofagus yang memakan tanaman yang dimakan manusia sering mengakibatkann kerugian secara ekonomi dalam jumlah yang besar.

Beberapa faktor yang dapat mempengaruhi tinggi-rendahnya intensitas dari serangan hama pada suatu varietas antara lain sifat fisik tanaman seperti panjang-pendek dan tebal-tipisnya bulu-bulu (trikoma) yang dimiliki oleh varietas tersebut. Selain itu, hal lain yang mempengaruhi intensitas serangan adalah kandungan kimia yang dimiliki oleh varietas tersebut. Kandungan kimia yang dimaksud tersebut merupakan kandungan kimia yang dapat menolak kehadiran hama atau yang biasa disebut dengan zat repellent dan kandungan yang dapat menarik kehadiran hama yang biasa disebut attaraktan.

Kepadatan, Frekuensi, Keanekaragaman dan Kemerataan: Jenis serangga hama yang memiliki nilai kepadatan paling tinggi selama pengamatan adalah $L$ indicata pada minggu pertama dengan nilai kepadatan sebesar 2.16 individu $/ \mathrm{m}^{2}$. Sedangkan jenis serangga hama yang memilik nilai kepadatan paling rendah adalah $P$. inclusa pada pengamatan minggu ketiga dengan nilai 0.6 individu $/ \mathrm{m}^{2}$.

Tabel 1. Kepadatan, Frekuensi dan Indeks Nilai Penting Serangga Hama pada Tanaman Kedelai

\begin{tabular}{|c|c|c|c|c|c|c|c|c|c|c|c|c|}
\hline \multirow{3}{*}{ Spesies } & \multicolumn{4}{|c|}{ Kepadatan $\left(\right.$ Ind $\left./ \mathbf{m}^{2}\right)$} & \multicolumn{4}{|c|}{ Frekuensi (\%) } & \multicolumn{4}{|c|}{ INP (\%) } \\
\hline & \multicolumn{4}{|c|}{ Minggu ke- } & \multicolumn{4}{|c|}{ Minggu ke- } & \multicolumn{4}{|c|}{ Minggu ke- } \\
\hline & 1 & 2 & 3 & 4 & 1 & 2 & 3 & 4 & 1 & 2 & 3 & 4 \\
\hline S. litura & 1.04 & 1.16 & 0.92 & 1.2 & 76 & 64 & 92 & 44 & 46 & 53 & 50 & 50 \\
\hline C. chalcites & 0.88 & 0.84 & 0.84 & 0.68 & 88 & 44 & 84 & 44 & 44 & 48 & 47 & 46 \\
\hline L. indicata & 2.16 & 1.56 & 1.52 & 1.72 & 80 & 68 & 88 & 60 & 68 & 62 & 63 & 67 \\
\hline P. inclusa & 0.68 & 0.8 & 0.6 & 0.64 & 72 & 64 & 84 & 52 & 42 & 37 & 40 & 37 \\
\hline
\end{tabular}


Frekuensi atau kekerapan dijumpainya individu suatu spesies pada saat pengamatan paling banyak adalah $S$. litura pada minggu ketiga dengan nilai frekuensi sebesar 92\%. Sedangkan spesies yang kurang dijumpai adalah $C$. chalcites pada minggu kedua dan keempat, dan $S$. litura pada minggu keempat dengan nilai frekuensi sebesar $42 \%$.

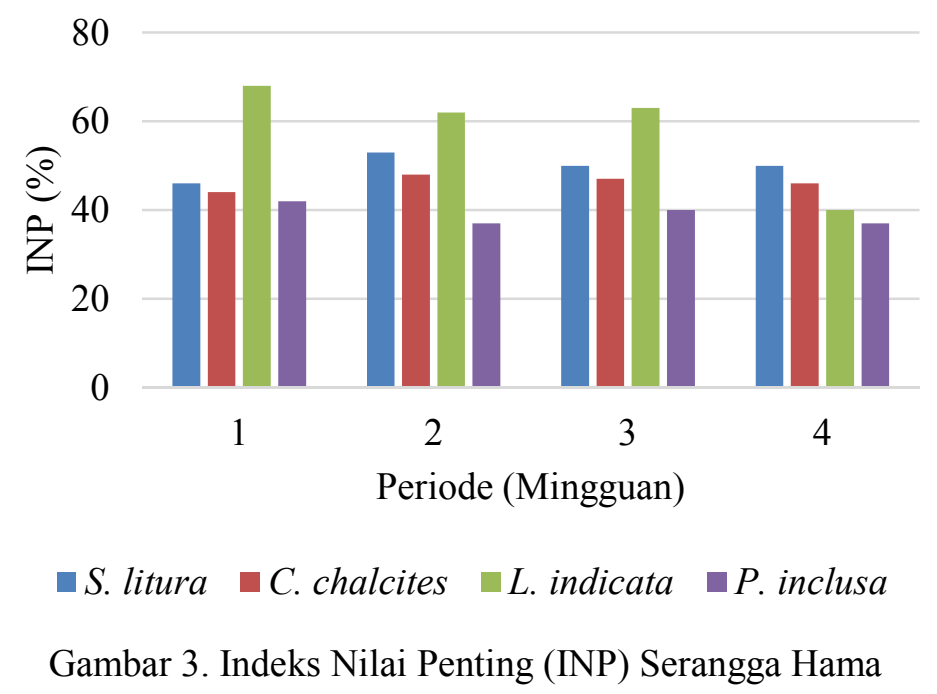

Dari Gambar 3 dapat dilihat hubungan dan peran dari keempat spesies yang ditemukan pada lahan pertanaman kedelai. Spesies yang memiliki nilai frekuensi kehadiran yang tinggi, memiliki nilai kepadatan yang tinggi pula. Dengan demikian, spesies yang paling berperan dalam lahan pertanaman kedelai yaitu L. indicata, S.litura, C. chalcites kemudian P. inclusa. Karena keempat spesies tersebut merupakan serangga hama maka, perannya dalam lahan pertanaman kedelai tetap merugikan. Jadi, perlu adanya tindakan pengendalian hama secara terpadu mengenai penekanan jumlah populasi dari serangga hama tersebut.

Tabel 2. Indeks Keanekaragaman dan Kemerataan Serangga Hama pada Tanaman Kedelai

\begin{tabular}{ccc}
\hline \multirow{2}{*}{ Minggu ke- } & \multicolumn{2}{c}{ Id } \\
\cline { 2 - 3 } & Keanekaragaman $\left(\mathrm{H}^{\prime}\right)$ & Kemerataan $(\mathrm{E})$ \\
\hline 1 & 1.28 & 0.92 \\
\hline 2 & 1.34 & 0.97 \\
\hline 3 & 1.32 & 0.95 \\
\hline 4 & 1.3 & 0.93 \\
\hline
\end{tabular}

Nilai dari indeks keanekaragaman menunjukkan bahwa jenis serangga hama pada tanaman kedelai rata-rata tiap minggunya adalah sedang. Artinya serangga hama tersebut cukup beragam dalam ekosistemnya. Dan untuk nilai dari indeks kemerataan rata-rata tiap minggunya menunjukkan bahwa serangga hama pada tanaman kedelai adalah dalam keadaan ekosistem yang stabil.

Distribus Jenis Serangga Hama: Sebaran jenis untuk populasi tiapspesies dari serangga hama pada tanaman kedelai varietas Anjasmoro di UPT Pengembangan Benih Palawija Singosari, Malang cenderung seragam (uniform), seperti yang terlihat pada Tabel 3. 
e-Jurnal Ilmiah BIOSAINTROPIS (BIOSCIENCE-TROPIC)

Volume 5/ No.: 2 / Halaman 1 - 9 / Januari Tahun 2016

ISSN : 2460-9455 (e) - 2338-2805(p)

Tabel 3. Pola Distribusi Jenis Serangga Hama

\begin{tabular}{|c|c|c|c|c|c|}
\hline \multirow{3}{*}{ Spesies } & \multicolumn{4}{|c|}{ Pola sebaran } & \multirow{3}{*}{ Rerata } \\
\hline & \multicolumn{4}{|c|}{ Minggu ke- } & \\
\hline & 1 & 2 & 3 & 4 & \\
\hline S. litura & $\begin{array}{c}\text { Seragam } \\
(0.19)\end{array}$ & $\begin{array}{c}\text { Seragam } \\
(0.25)\end{array}$ & $\begin{array}{c}\text { Seragam } \\
(0.14)\end{array}$ & $\begin{array}{c}\text { Seragam } \\
(0.03)\end{array}$ & 0.15 \\
\hline L. indicata & $\begin{array}{c}\text { Seragam } \\
(0.24)\end{array}$ & $\begin{array}{c}\text { Seragam } \\
(0.22)\end{array}$ & $\begin{array}{c}\text { Seragam } \\
(0.22)\end{array}$ & $\begin{array}{c}\text { Seragam } \\
(0.12)\end{array}$ & 0.2 \\
\hline P. inclusa & $\begin{array}{c}\text { Seragam } \\
(0.36)\end{array}$ & $\begin{array}{c}\text { Seragam } \\
(0.17)\end{array}$ & $\begin{array}{c}\text { Seragam } \\
(0.16)\end{array}$ & $\begin{array}{c}\text { Seragam } \\
(0.02)\end{array}$ & 0.17 \\
\hline C. chalcites & $\begin{array}{c}\text { Seragam } \\
(0.21)\end{array}$ & $\begin{array}{c}\text { Seragam } \\
(0.32)\end{array}$ & $\begin{array}{c}\text { Seragam } \\
(0.07)\end{array}$ & $\begin{array}{c}\text { Seragam } \\
(0.18)\end{array}$ & 0.19 \\
\hline Rerata & 0.25 & 0.24 & 0.15 & 0.09 & \\
\hline
\end{tabular}

Pada Tabel. 3 di atas dapat dilihat bahwa keempat spesies tersebut dalam tingkat populasi berdistribusi dengan pola seragam (uniform), hal ini berdasarkan nilai perhitungan Indeks Morishita pada tiap spesies menunjukkan angka di bawah 1 yaitu dengan nilai rata-rata seluruh spesies tiap minggunya $0.15,0.2,0.17$, dan 0.19 . Pola penyebaran seragam yang terjadi pada persebaran serangga hama menunjukkan bahwa terdapat pola tingkah laku yang tidak selektif dengan kata lain secara tidak langsung terdapat faktor pembatas disebabkan tempat hidup yang heterogen.

Korelasi Antara Faktor Abiotik dengan Nilai Indeks Morisita Serangga Hama: Untuk mengetahui bahwa faktor abiotik yang diukur berpengaruh atau tidak terhadap pola sebaran serangga hama pada tanaman kedelai dilakukan analisis korelasi antara nilai indeks sebaran morishita serangga hama dengan suhu dan kelembaban. Hasil analisis korelasi ditampakkan pada Gambar 4.

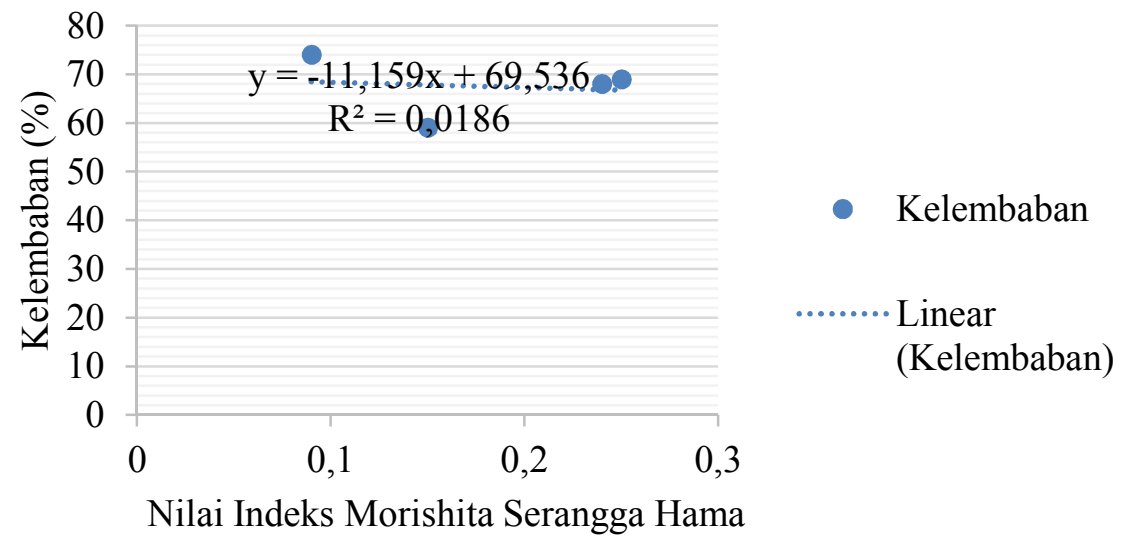

Gambar 4. Korelasi Antara Kelembaban dengan Nilai Indeks Morishita Serangga Hama 
Grafik korelasi antara suhu dengan nilai Indeks Morishita serangga hama menunjukkan nilai koefisien determinasi $\mathrm{R}^{2}$ sebesar 0.486 , dengan mengakarkan nilai 0.486 didapatkan hasil 0.684 . Hasil pengakaran tersebut merupakan koefisien korelasinya. Hal ini berarti nilai rata-rata Indeks Morisita serangga hama tiap minggu sebesar $48.6 \%$ dipengaruhi oleh suhu, melalui persamaan regresi $y=-15.308 x+22.544$, sisanya $51.4 \%$ dipengaruhi oleh faktor lain. Jadi, suhu terhadap persebaran serangga hama memiliki pengaruh dengan nilai sebesar 48.6\%. Dan selisih antara nilai 100\% dengan persentase faktor suhu yaitu sebesar $51.4 \%$ merupakan faktor lain yang dapat mempengaruhi pola sebaran serangga hama pada tanaman kedelai.

Harga $r$ tabel untuk signifikansi 0.05 dengan $n=2$ yaitu 0.9 dan untuk signifikansi 0.01 yaitu 0.98 . Karena harga $r$ hitung lebih kecil dari $r$ tabel untuk signifikansi $0.05(0.486<0.9)$ maupun $0.01(0.486$ $<0.98$ ), maka dapat disimpulkan bahwa antara dua variabel tersebut korelasinya tidak nyata. Artinya suhu tidak berpengaruh terhadap pola persebaran serangga hama pada tanaman kedelai.

Grafik korelasi antara kelembaban dengan nilai Indeks Morishita serangga hama menunjukkan nilai koefisien determinasi $\mathrm{R}^{2}$ sebesar 0.0186 , dengan mengakarkan nilai 0.0186 didapatkan hasil 0.136 . Hasil pengakaran tersebut merupakan koefisien korelasinya. Hal ini berarti nilai rata-rata Indeks Morisita serangga hama tiap minggu sebesar $1.86 \%$ dipengaruhi oleh kelembaban, melalui persamaan regresi $y=-11.159 x+69.536$, sisanya $98.14 \%$ dipengaruhi oleh faktor lain. Jadi, kelembaban terhadap persebaran serangga hama pada tanaman kedelai mempunyai pengaruh yang sangat kecil yaitu hanya sebesar $1.8 \%$. Dan selisih antara nilai $100 \%$ dengan persentase faktor kelembaban yaitu sebesar $98.14 \%$ merupakan faktor lain yang dapat mempengaruhi pola sebaran serangga hama pada tanaman kedelai.

Harga $r$ tabel untuk signifikansi 0.05 dengan $n=2$ yaitu 0.9 dan untuk signifikansi 0.01 yaitu 0.98 karena harga $r$ hitung lebih kecil dari $r$ tabel untuk signifikansi $0.05(0.0186<0.9)$ maupun $0.01(0.0186$ $<0.98$ ), maka dapat disimpulkan bahwa antara dua variabel tersebut korelasinya tidak nyata. Artinya sama halnya dengan suhu, kelembaban tidak berpengaruh terhadap pola persebaran serangga hama pada tanaman kedelai.

Dengan demikian faktor abiotik yang diukur tidak berpengaruh terhadap pola sebaran serangga hama pada tanaman kedelai di UPT Pengembangan Benih Palawija Singosari, Malang.

\section{Kesimpulan}

Spesies yang ditemukan pada tanaman kedelai fase generatif di UPT Pengembangan Benih Palawija Singosari, Malang adalah Spodoptera litura, Lamprosema indicate, Phaedonia inclusa dan Chrysodeixis chalcites. Serangga hama S. litura, L. indicate, P. inclusa dan C. chalcites, pada pertanaman kedelai berdistribusi dengan pola seragam (uniform) yaitu dengan nilai rata-rata tiap spesies tiap minggunya $0.15,0.2,0.17$, dan 0.19 . Berdasarkan hasil analisis data korelasi, faktor abiotik yang diukur yaitu suhu dan kelembaban tidak berpengaruh terhadap pola sebaran individu serangga hama pada tanaman kedelai.

\section{Ucapan Terima Kasih}

Kepada pihak UPT Pengembangan Benih Palawija Singosari, Malang

\section{Daftar Pustaka}

[1] Adisarwanto, T., 2013. Kedelai Tropika Produktivitas 3 ton/ha, Jakarta: Penebar Swadaya. 
e-Jurnal Ilmiah BIOSAINTROPIS (BIOSCIENCE-TROPIC)

Volume 5/ No.: 2 / Halaman 1 - 9 / Januari Tahun 2016

ISSN : 2460-9455 (e) - 2338-2805(p)

[2] Radiyanto, I., Sodiq, M., dan Nurcahyani, N.M., 2010. Keanekaragaman Serangga Hama dan Musuh Alami pada Lahan Pertanaman Kedelai di Kecamatan Balong-Ponorogo. Jurnal Entomologi Indonesia, 7(2), pp.116-121.

[3] Campbell, N.A., Reece, J.B., Urry, L.A., Cain, M.L., Wassermen, S. A., and Minorsky, P. V., 2010. Biologi 8th ed. P. Hardani, W. dan Adhika, ed., Erlangga. Jakarta.

[4] Elfisuir, 2010. Ekologi Populasi. Biologi FKIP Uiversitas Islam Riau. Akses 27 Maret 2017. URL:http://elfisuir.blogspot.co.id/2010/03/ekologi-populasi.html

[5] Lilis, C.S., 2004. Kunci Determinasi Serangga. Kanisius. Yogyakarta.

[6] Borror, D.J., Triplehorn, C.A., and Johnson, N.F. 1992. Pengenalan Pelajaran Serangga (Penerjemah: Soetiyono). Gadjahmada University Press. Yogyakarta.

[7] Fattah, A. dan Ilyas, A., 2016. Siklus Hidup Ulat Grayak ( Spodoptera litura, F ) dan Tingkat Serangan pada Beberapa Varietas Unggul Kedelai di Sulawesi Selatan. Prosiding Seminar Nasional Inovasi Teknologi Pertanian. Banjarbaru, pp. 824-832. URL: http://kalsel.litbang.pertanian.go.id/ind/images/pdf/Semnas2016/103_abdul_fattah.pdf. 